\title{
Molecular Analysis of Human Influenza Virus in Tehran, Iran
}

\author{
Z. Soltani $i^{a} b \quad$ M. Hosseinib ${ }^{b}$ M. Shahidia ${ }^{a}$ M. Hedayatic $\quad$ M.T. Kheiri ${ }^{a}$ \\ a Influenza Unit, Pasteur Institute of Iran, b Department of Microbiology, Faculty of Biological Sciences, \\ Shahid-Beheshti University, Tehran, Iran; ' Department of Biochemistry and Molecular Biology, Bloomberg School \\ of Public Health, Johns Hopkins University, Baltimore, Md., USA
}

\section{Key Words}

A/H1N1 $\cdot$ A/H3N2 $\cdot$ Hemagglutinin gene $\cdot$ Influenza virus, Tehran · Phylogenetic analysis

\begin{abstract}
Background: To date there are no reports of molecular and phylogenetic analyses of human influenza virus in Tehran, Iran. Objectives: We isolated and characterized circulating influenza viruses in a sample of patients in Tehran. Methods: Nasal and pharyngeal swabs were collected from 57 individuals who were suspected of having influenza between October 2005 and January 2007. These samples were cultured and subsequently genotyped by RT-PCR and sequencing analyses. Results: Twelve of 57 samples (21\%) were positive for human influenza virus. Out of the 12 positive samples, 7 were $\mathrm{A} / \mathrm{H} 3 \mathrm{~N} 2$ (58\%), 3 were $\mathrm{A} / \mathrm{H} 1 \mathrm{~N} 1$ (25\%) and 2 were $\mathrm{B}$ subtypes (17\%). The phylogenetic analysis of the hemagglutinin gene showed that the H1N1 isolates were close to the $\mathrm{A} /$ New Caledonia/20/99 and the H3N2 isolates were close to the A/Panama/2007/99 and A/Moscow/10/99 vaccine strains. Conclusion: In a sample of clinical patients in Tehran, Iran, the predominant subtype of human influenza virus was determined to be $\mathrm{A} / \mathrm{H} 3 \mathrm{~N} 2$, followed by $\mathrm{A} / \mathrm{H} 1 \mathrm{~N} 1$ and $\mathrm{B}$. In addition, phylogenetic analysis on $\mathrm{H} 1$ showed some genetic drifts from vaccine strains, but the phylogeny of $\mathrm{H} 3$ demonstrated that these isolates were from the previous vaccine strains.

Copyright $\odot 2009$ S. Karger AG, Basel
\end{abstract}

\section{Introduction}

Human influenza viruses continually circulate and cause yearly epidemics. Novel strains emerge sporadically as pandemic viruses $[1,2]$. The surface hemagglutinin (HA) glycoprotein of influenza viruses is the major target for neutralizing antibodies, and point mutations in the potential antigenic domains of this protein are thought to allow viruses to evade established immune antibodies in the human population. Analyses of epidemic influenza virus isolates, therefore, have chiefly focused on antigenic characterization of the HA glycoprotein in order to detect new variants of each epidemic strain for the recommendation of vaccine strains in each season $[3,4]$. Annual epidemics are caused by the rapid evolution of the viral genome. Such changes can be monitored through antigenetic analysis and gene sequencing, particularly the gene that codes for viral HA.

There are a few reports of human influenza viruses from Iran, a seroepidemiological description published in 2004 [5] and a more recent molecular and phylogenetic analysis in Shiraz [6]. Here, we collected a sample of human influenza viruses in Tehran during the 20062007 influenza seasons. We used molecular techniques to determine the typing and subtyping of human influenza virus on these samples. The data obtained were then compared to the vaccine strains that were recommended by the WHO for the same period.

\section{KARGER}

Fax +4161306 1234 E-Mail karger@karger.ch www.karger.com (c) 2009 S. Karger AG, Basel

$0300-5526 / 09 / 0522-0063 \$ 26.00 / 0$

Accessible online at:

www.karger.com/int
Masoumeh Tavasoti Kheiri, PhD

Influenza Unit, Institute Pasteur of Iran

12 Farvardin St.

Tehran (Iran)

Tel. +98 216695 3311, Fax +98 216640 9467, E-Mail mtkheiri@pasteur.ac.ir 


\section{Methods}

We collected 57 nasopharyngeal swabs from individuals suspected of having influenza. The samples were collected in a clinic and at the influenza unit of the Pasteur Institute in Tehran, Iran, between October 2005 and January 2007.

The MDCK continuous cell line was used to isolate influenza viruses in cell culture. Cells were seeded at a concentration of 5 $\times 10^{6} \mathrm{cells} / \mathrm{ml}$. After 1 day, $200 \mu \mathrm{l}$ of each sample was inoculated into wells containing MDCK cells. The culture medium was then examined for hemagglutinin activity using a $0.5 \%$ suspension of chicken erythrocytes.

Viral RNA was extracted from $300 \mu \mathrm{l}$ of each sample using a commercial RNX-Plus ${ }^{\mathrm{TM}}$ solution (CinnaGen, Tehran, Iran) and immediately frozen at $-70^{\circ}$. The cDNA synthesis was performed using SuperScript ${ }^{\mathrm{TM}}$ III first strand synthesis kit (Invitrogen, Carlsbad, Calif., USA) according to the manufacturer's instructions. Amplification of each RNA segment was carried out by RTPCR, as described previously [6]. The isolates were selected for molecular characterization using bi-directional sequencing. The H1 (543 bp) and H3 (292 bp) fragments from influenza A virus and NS (334 bp) segment from influenza B were used for sequencing and phylogenetic analysis. The PCR products were sequenced in both directions by a CEQ ${ }^{\mathrm{TM}} 2000$ dye terminator cycle sequencing kit (Beckman Coulter, Fullerton, Calif., USA) using an automated CEQ 2000XL microcapillary DNA analysis sequencing apparatus (Beckman Coulter). Alignment was performed using Clustal X software, version 1.81 [7].

GenBank accession numbers for sequences determined in this work are EU311401-EU311412.

Phylogenetic trees were constructed using the neighbor-joining method [8]. Bootstrap analysis $(n=1,000)$ was performed to determine the best fitting tree for each gene [9]. Genetic distance was estimated by the Kimura 2-parameter matrix [10]. Molecular Evolution Genetic Analysis (MEGA) computer software, version 2.1 [11], was utilized in this study for phylogenetic and molecular evolutionary analysis and nucleotide differences within and between the isolate sequences.

\section{Results}

A total of 12 of 57 samples were found to be positive for human influenza virus (21\%). Molecular typing by RT-PCR and subtyping of the positive samples showed 7 as influenza $\mathrm{A} / \mathrm{H} 3 \mathrm{~N} 2$ (58\%), 3 as influenza A/H1N1 (25\%) and 2 as influenza B (17\%).

The nucleotide and amino acid sequences of the HAl (for type A) and NS (for type B) of the Iran-Tehran isolates were compared with other sequences in GenBank, and with the vaccine strains, during the 2005-2007 influenza seasons.

Among Tehran H1N1 isolates, maximum similarity (99\%) was observed with the A/Philipin/67/2004 strain and $95-98 \%$ with the A/New Caledonia/20/99 strain. These isolates contained 1-3 amino acid differences compared with A/New Caledonia/20/99 (table 1). In Tehran $\mathrm{H} 3 \mathrm{~N} 2$ isolates, maximum similarity (99\%) was observed with the A/Panama/2007/1999. The 2005-H3N2 isolates showed $81-93 \%$ homology to A/California/7/2004 (H3N2)

Table 1. Amino acid substitution of hemagglutinin from H1N1 influenza virus isolates in Tehran compared to vaccine strains

\begin{tabular}{|c|c|c|c|}
\hline \multirow[t]{2}{*}{ Virus strain } & \multicolumn{3}{|c|}{ Amino acid position } \\
\hline & H1N1: 229 & 252 & 254 \\
\hline A/New Caledonia/20/99 & $\mathrm{D}$ & $\mathrm{N}$ & $\mathrm{N}$ \\
\hline Tehran/7/2007 & G & - & - \\
\hline Tehran/11/2007 & G & $\mathrm{Y}$ & S \\
\hline
\end{tabular}

Table 2. Amino acid substitution of hemagglutinin from $\mathrm{H} 3 \mathrm{~N} 2$ influenza virus isolates in Tehran compared to vaccine strains

\begin{tabular}{|c|c|c|c|c|c|c|c|c|c|c|c|c|c|c|c|c|c|c|c|}
\hline \multirow[t]{2}{*}{ Virus strain } & \multicolumn{19}{|c|}{ Amino acid position } \\
\hline & 162 & 163 & 172 & 186 & 188 & 189 & 190 & 192 & 193 & 197 & 220 & 222 & 225 & 226 & 227 & 246 & & & \\
\hline A/California/7/2004 & $\mathrm{P}$ & A & $\mathrm{E}$ & G & $\mathrm{N}$ & $\mathrm{N}$ & $\mathrm{D}$ & I & S & Q & $\mathrm{R}$ & $\mathrm{R}$ & $\mathrm{D}$ & I & $\mathrm{P}$ & $\mathrm{N}$ & & & \\
\hline Tehran/25/2005 & $\mathrm{H}$ & $\mathrm{L}$ & - & $\mathrm{S}$ & $\mathrm{D}$ & $\mathrm{S}$ & - & - & - & - & $\mathrm{S}$ & W & G & $\mathrm{V}$ & $\mathrm{S}$ & $\mathrm{Y}$ & & & \\
\hline Tehran/27/2005 & $\mathrm{H}$ & $\mathrm{F}$ & G & $S$ & $\mathrm{D}$ & $\mathrm{K}$ & $\mathrm{E}$ & $\mathrm{T}$ & $\mathrm{N}$ & $\mathrm{R}$ & - & $\mathrm{W}$ & G & $\mathrm{L}$ & $S$ & $\mathrm{Y}$ & & & \\
\hline H3N2: & 165 & 172 & 182 & 186 & 189 & 190 & 192 & 193 & 194 & 196 & 197 & 202 & 220 & 222 & 223 & 225 & 226 & 227 & 246 \\
\hline $\mathrm{A} / \mathrm{Wisconsin} / 67 / 2005$ & $\mathrm{~N}$ & $\mathrm{E}$ & $\mathrm{V}$ & $\mathrm{V}$ & $\mathrm{N}$ & $\mathrm{D}$ & I & $\mathrm{F}$ & $\mathrm{L}$ & $\mathrm{A}$ & Q & I & $\mathrm{R}$ & $\mathrm{R}$ & I & $\mathrm{N}$ & I & $\mathrm{P}$ & $\mathrm{N}$ \\
\hline Tehran/1/2007 & - & - & - & G & - & - & - & $\mathrm{S}$ & - & - & - & - & - & - & $\mathrm{V}$ & $\mathrm{D}$ & - & - & $\mathrm{Y}$ \\
\hline Tehran/6/2007 & - & - & - & $\mathrm{S}$ & $\mathrm{S}$ & - & - & $\mathrm{S}$ & I & - & - & $\mathrm{V}$ & $\mathrm{S}$ & $\mathrm{W}$ & $\mathrm{V}$ & G & $\mathrm{V}$ & $\mathrm{S}$ & - \\
\hline Tehran/9/2007 & - & - & - & $\mathrm{S}$ & $\mathrm{S}$ & - & - & $\mathrm{S}$ & I & - & - & $\mathrm{V}$ & $S$ & $\mathrm{~W}$ & $\mathrm{~V}$ & G & $\mathrm{V}$ & $\mathrm{S}$ & - \\
\hline Tehran/14/2007 & I & - & - & $\mathrm{S}$ & $S$ & - & - & $S$ & I & - & - & $\mathrm{V}$ & $\mathrm{S}$ & $\mathrm{W}$ & $\mathrm{V}$ & G & $\mathrm{V}$ & $\mathrm{S}$ & - \\
\hline Tehran/16/2007 & - & G & $\mathrm{I}$ & $\mathrm{S}$ & $\mathrm{K}$ & $\mathrm{E}$ & $\mathrm{T}$ & $\mathrm{N}$ & - & I & $\mathrm{R}$ & $\mathrm{V}$ & - & $\mathrm{W}$ & $\mathrm{V}$ & $\mathrm{G}$ & $\mathrm{L}$ & S & - \\
\hline
\end{tabular}


Fig. 1. A neighbor-joining phylogenetic tree of the HA1 gene nucleotide sequence of Iranian isolates and reference gene for $\mathrm{H} 1 \mathrm{~N} 1$ (a) and H3N2 (b) strains. Bootstrap values based on 1,000 replicates are shown at each main branch. Bootstrap values below $70 \%$ are not shown. The scale bar indicates $1 \%$ nucleotide divergence. Iranian isolates are marked. = Iranian isolates in last study [Ref. 6]; $\mathbf{\square}=$ Iranian isolates in this study; $\square=$ the strains near to Iranian isolates; $\boldsymbol{\Delta}$ = vaccine strains.

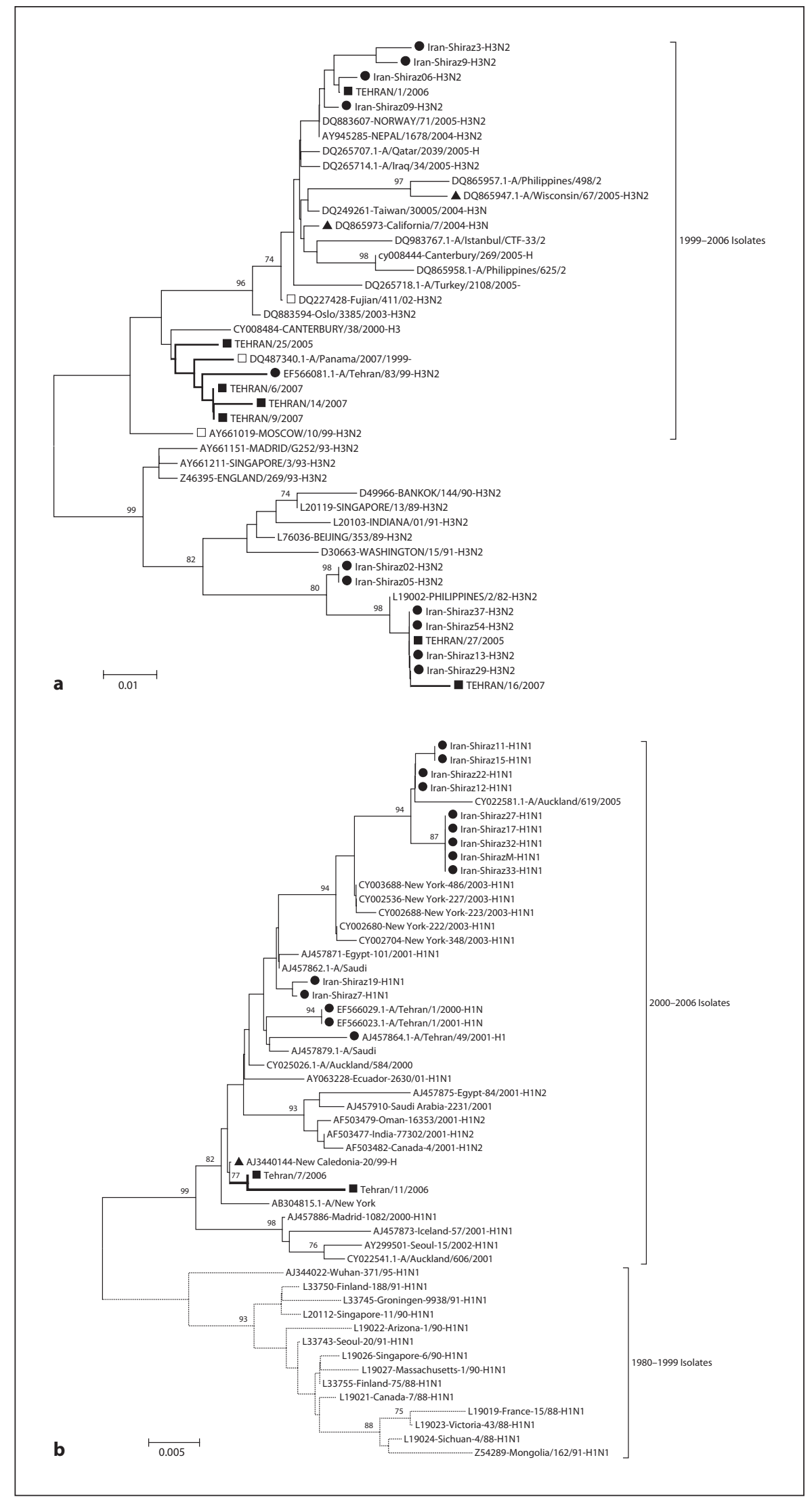

Intervirology 2009;52:63-67 
and $2006-\mathrm{H} 3 \mathrm{~N} 2$ isolates showed $83 \%$ to $99 \%$ similarity to A/Wisconsin/67/2005 vaccine strains. Alignment of the amino acids of the HA protein demonstrated 10-13 amino acid changes in 2005-H3N2 isolates and 5-15 amino acid changes in 2006-H3N2 isolates, in comparison with candidate vaccine strains (table 2). Tehran B isolates were very close to Florida/02/2006, with $100 \%$ homology. As the HA gene was used in vaccine strains, we could not compare Tehran B isolates with vaccine strains.

The 12 positive isolates were selected for phylogenetic analysis. In the $\mathrm{H} 1 \mathrm{~N} 1$ phylogenetic tree, Tehran isolates were clustered only in the recently discovered isolates of 2000-2006 (fig. 1a). However, in H3N2 phylogenetic tree, some Tehran isolates were clustered with the 1980-1999 strains while others were clustered with the 2000-2006 lineages (fig. 1b). Phylogenetic analysis of Tehran H1N1 isolates confirmed that $\mathrm{H} 1 \mathrm{~N} 1$ isolates were branched in a unique cluster close to $\mathrm{A} / \mathrm{New}$ Caledonia-like vaccine virus, with a $77 \%$ bootstrap value. The phylogeny of the H3N2 HA nucleotide sequence indicated that Tehran isolates were from the Wisconsin/67/2005 and A/California/7/2004 strains. They were branched in a cluster close to A/Panama/2007/1999- and A/Moscow/10/99-like vaccine strains.

\section{Discussion}

The importance of predicting the emergence of new circulating influenza strains for subsequent annual vaccine development cannot be underestimated [12]. On the basis of WHO reports, during the 2005-2006 influenza seasons A/New Caledonia/20/99- (H1N1) and A/California/7/04-like (H3N2) were dominant [13]. Tehran H3N2 and $\mathrm{H} 1 \mathrm{~N} 1$ nucleotide sequence isolates were compared to the $\mathrm{HA} 1$ of other $\mathrm{H} 3 \mathrm{~N} 2$ and $\mathrm{H} 1 \mathrm{~N} 1$ reference virus isolates from GenBank. This analysis revealed that Tehran H1N1 isolates were related to the $\mathrm{A} / \mathrm{New}$ Caledonia/20/99 vaccine strain and clustered in a unique branch. The H3N2 phylogenetic analysis showed that some Tehran H3N2 isolates were closely linked with the Iranian isolates from previous years and some were related to A/Moscow/10/99 and A/Panama/2007/1999 strains.

Amino acid comparison further supported the result of the sequence phylogenetic analysis. Between 1 and 3 amino acid differences in the HAl protein were observed between Tehran H1N1 isolates and A/New Caledonia/20/99. In 2005-H3N2 isolates 10-13 amino acid changes and in 2006-H3N2 isolates 5-15 amino acid differences were observed when compared with the candidate vaccine strains.

The HA1 subunit of the influenza A protein consists of the globular head and contains 5 major antibody binding sites (A-E). Further analysis will be necessary to better understand the evolution of the mutational changes observed [14]. Wilson and Cox [15] proposed that an epidemiologically important drift variant usually contains 4 or more amino acid substitutions located in 2 or more antigenic sites on $\mathrm{HA} 1$ protein. Amino acid substitutions in Tehran H1N1 isolates were not located in these major antigenetic sites (table 1). However, the amino acid substitutions in the H3N2 isolates were located in the antigenic sites $\mathrm{B}$ and $\mathrm{D}$. It was also confirmed that Tehran $\mathrm{H} 3 \mathrm{~N} 2$ isolates were generated from the previous vaccine strains.

In conclusion, human influenza A/H3N2, A/H1N1 and $\mathrm{B}$ were dominant in a sample of patients in Tehran during the 2006-2007 influenza seasons. In addition, phylogenetic analysis on $\mathrm{H} 1$ showed some genetic drift among these samples from vaccine strains, but the phylogeny of $\mathrm{H} 3$ demonstrated that these isolates were from the previous vaccine strains generation.

\section{Acknowledgment}

This study was supported by grant no. 295 from the Iranian Molecular Medicine Network, Pasteur Institute of Iran.

\section{References}

Webster RG, Bean WJ, Gorman OT, Chambers TM, Kawaoka Y: Evolution and ecology of influenza A viruses. Microbiol Rev 1992; 56:152-179.

2 Cox NJ, Subbarao K: Global epidemiology of influenza: past and present. Annu Rev Med 2000;51:407-421.
Ellis JS, Chakraverty P, Clewley JP: Genetic and antigenetic variation in the hemagglutinin of recently circulating human influenza A (H3N2) viruses in the United Kingdom. Arch Virol 1995;140:1889-1904.

4 Lindstrom SL, Sugita S, Endo A, Ishida M, Huang P, Xi SH, Nerome K: Evolutionary characterization of $\mathrm{H} 3 \mathrm{~N} 2$ influenza viruses: novel changes in the receptor binding domain. Arch Virol 1996;141:1349-1355. 
5 Mokhtari-Azad T, Mohammadi H, Moosavi IA, Saadatmand Z, Nategh R: Influenza surveillance in the Islamic Republic of Iran. East Mediterr Health J 2004;10:315-321

66 Shahidi M, Kheiri MT, Olyaee SAB, Hosseini M, Moattari A, Tabatabaiean M, Bashar R, Forooshani RS, Mahboudi F: Molecular and phylogenetic analysis of human influenza virus among Iranian patients in Shiraz, Iran. J Med Virol 2007;79:803-810.

7 Thompson JD, Gibson TJ, Plewniak F, Jeanmougin F, Higgins DG: The CLUSTAL_X windows interface: flexible strategies for multiple sequence alignment aided by quality analysis tools. Nucleic Acids Res 1997;25: 4876-4882.
Saitou N, Nei M: The neighbor-joining method: a new method for reconstructing phylogenetic trees. Mol Biol Evol 1987;4: 406-425.

-9 Dopazo J: Estimating errors and confidence intervals for branch lengths in phylogenetic trees by a bootstrap approach. J Mol Evol 1994;38:300-304.

10 Kimura M: A simple method for estimating evolutionary rates of base substitutions through comparative studies of nucleotide sequences. J Mol Evol 1980;16:111-120.

11 Kumar S, Tamura K, Jakobsen IB, Nei M: MEG A2: molecular evolutionary genetic analysis software. Bioinformatics 2001;17: 1244-1245.
12 Gensheimer KF, Fukuda K, Brammer L, Cox N, Patriarca PA, et al: Preparing for pandemic influenza: the need for enhanced surveillance. Emerg Infect Dis 1999;5:297-299.

13 Centers for Disease Control and Prevention: 2005-2006 US influenza season summary. www.cdc.gov/flu/weekly/fluactivity.htm.

14 Daum L, Canas LC, Smith BC, Klimov A, Huff W, Barnes W, Lohman KL: Genetic and antigenic analysis of the first A/New Caledonia/20/99-like H1N1 influenza isolates reported in the Americas. Emerg Infect Dis 2002;8:408-412.

15 Wilson I, Cox NJ: Structural basis of immune recognition of influenza virus hemagglutinin. Annu Rev Immunol 1990;8:737771 . 